bioRxiv preprint doi: https://doi.org/10.1101/2022.03.03.482795; this version posted March 3, 2022. The copyright holder for this preprint (which was not certified by peer review) is the author/funder, who has granted bioRxiv a license to display the preprint in perpetuity. It is made available under aCC-BY-NC-ND 4.0 International license.

\title{
1 Soluble signal inhibitory receptor on leukocytes-1 is released from activated neutrophils by
}

\section{2 proteinase 3 cleavage}

3

4 Helen J. von Richthofen *, Geertje H.A. Westerlaken *, Doron Gollnast *, Sjanna Besteman †, Eveline M. Delemarre $\ddagger$, Karlijn

5 Rodenburg $\ddagger$, Petra Moerer $\ddagger$, Daphne A.C. Stapels $\S$, Anand K. Andiappan $\uparrow$, Olaf Rötzschke $\uparrow$, Stefan Nierkens $\ddagger$, Helen L.

6 Leavis |I, Louis J. Bont + , Suzan H.M. Rooijakkers §, Linde Meyaard *

* Center of Translational Immunology, University Medical Center Utrecht, Lundlaan 6, 3584 EA, Utrecht, the Netherlands; Oncode Institute, University Medical Center Utrecht, Lundlaan 6, 3584 EA, Utrecht, the Netherlands

† Department of Pediatrics, Wilhelmina Children's Hospital, University Medical Centre Utrecht, Utrecht, Lundlaan 6, 3584, EA, Utrecht, the Netherlands; Center of Translational Immunology, University Medical Centre Utrecht, Utrecht, Lundlaan 6, 3584, EA, Utrecht, the Netherlands

¥ Center of Translational Immunology, University Medical Center Utrecht, Lundlaan 6, 3584 EA, Utrecht, the Netherlands $\S$ Department of Medical Microbiology, University Medical Center Utrecht, Utrecht University, Utrecht, Netherlands I Singapore Immunology Network, Agency for Science, Technology and Research, Singapore

E-mail address: L.Meyaard@umcutrecht.nl 
Signal inhibitory receptor on leukocytes-1 (SIRL-1) is an immune inhibitory receptor expressed on human granulocytes and monocytes which dampens antimicrobial functions. We previously showed that sputum neutrophils from infants with severe respiratory syncytial virus (RSV) bronchiolitis have decreased SIRL-1 surface expression compared to blood neutrophils, and that SIRL-1 surface expression is rapidly lost from in vitro activated neutrophils. This led us to hypothesize that activated neutrophils lose SIRL-1 by ectodomain shedding. Here, we developed an ELISA and measured the concentration of soluble SIRL-1 (sSIRL-1) in RSV bronchiolitis and hospitalized COVID-19 patients, which are both characterized by neutrophilic inflammation. In line with our hypothesis, SSIRL-1 concentration was increased in sputum compared to plasma of RSV bronchiolitis patients, and in serum of hospitalized COVID-19 patients compared to control serum. In addition, we show that in vitro activated neutrophils release SSIRL-1 by proteolytic cleavage, which can be prevented by proteinase 3 inhibition. Finally, we found that SIRL-1 shedding is prevented by extracellular adherence protein (Eap) from S. aureus. Notably, we recently showed that SIRL-1 is activated by PSM 3 from S. aureus, suggesting that S. aureus may counteract SIRL-1 shedding to benefit from preserved inhibitory function of SIRL-1. In conclusion, we are the first to report that SIRL-1 is released from activated neutrophils by proteinase 3 cleavage and that endogenous SSIRL-1 protein is present in vivo. 


\section{INTRODUCTION}

39

40

Immune inhibitory receptors (IIRs), also referred to as immune checkpoints, are pivotal in negative regulation of immune cells $(1,2)$. Although far less studied than the transmembrane form, many IIRs also have a soluble form or homologue $(3,4)$. Soluble IIRs can arise from ectodomain shedding of the membrane-expressed receptor $(5,6)$, or can be a product of alternative splicing $(7,8)$ or a homologous gene (9). Soluble IIRs were found to be increased in the circulation of patients with several forms of cancer (reviewed by (3)), sepsis (10), and COVID-19 (11).

Signal inhibitory receptor on leukocytes-1 (SIRL-1), encoded by the VSTM1 gene, is an IIR that is expressed on human monocytes and granulocytes in peripheral blood (12-14) and lung (15). On monocytes, but not granulocytes, SIRL-1 expression is associated with the single nucleotide polymorphism (SNP) rs612529T/C (14, 15). SIRL-1 inhibits innate effector functions such as Fc Receptor $(F C R)$ induced production of reactive oxygen species $(R O S)(14,16,17)$ and formation of neutrophil extracellular traps $(\mathrm{NET})(17,18)$. We recently showed that SIRL-1 recognizes amphipathic $\alpha$-helical peptides, including cathelicidin LL-37 and Staphylococcal phenol-soluble modulins (PSMs) (19), as all well as several members of the S100 protein family (20), classifying SIRL-1 as an inhibitory pattern recognition receptor (21).

We previously showed that SIRL-1 surface expression on neutrophils and monocytes rapidly decreases after activation in vitro (16). Here, we hypothesized that activated neutrophils and monocytes shed the ectodomain of SIRL-1, thereby releasing soluble SIRL-1 (sSIRL-1). In addition, it has been described that VSTM1 encodes the splice variant VSTM1-v2, which lacks the exon that encodes the transmembrane domain and is therefore predicted to give rise to a soluble form of SIRL1 (22). Even though these potential sources of SSIRL-1 have been reported, presence of endogenous SSIRL-1 protein has not been demonstrated yet. In this study, we developed an ELISA to investigate the presence and release mechanism of SSIRL-1 protein. 


\section{MATERIALS \& METHODS}

\section{Antibodies}

We previously described the production of the SIRL-1 specific monoclonal antibodies (mAbs) clone 1A5 (12) and 3D3 (19). The SIRL-1 specific mAb clone 3F5 (IgG2a isotype) was produced in a similar fashion, with the exception that mice were immunized with a SIRL-1 expressing cell line instead of Fclabeled SIRL-1 ectodomain. The 1A5 and 3F5 mAbs were conjugated with Alexa Fluor 647 (AF647) (Thermo Fisher Scientific) for flow cytometry. The 3D3 mAb was conjugated with biotin (Thermo Scientific) for the SSIRL-1 ELISA.

For antibody competition assays, peripheral blood mononuclear cells (PBMCs) were preincubated for 2 hours at $37^{\circ} \mathrm{C}$ with respective mAb clones. Subsequently, 1A5-AF647 was added to the PBMCs and incubated for 20 minutes at $4^{\circ} \mathrm{C}$, followed by two washes with FACS buffer (PBS containing $1 \%$ BSA and $0.01 \%$ NaN3). SIRL-1 expression was then measured by flow cytometry.

\section{Biological samples}

To isolate plasma for the ELISA spike experiment (Fig 1E) or for cell isolations, heparinized blood was obtained from healthy volunteers at the UMC Utrecht. For the rs612529T/C cohort, plasma and genotyping information was obtained from healthy volunteers from the Singapore Systems Immunology Cohort (SSIC) (23). For the RSV cohort, sputum, heparinized plasma and urine were obtained from infants with severe RSV bronchiolitis or control infants without infectious disease that were mechanically ventilated. These patients and the sputum isolation have been previously described (17). Briefly, sputum was collected by flushing tracheobronchial aspiration with a maximum of $2 \mathrm{~mL}$ normal saline. Sputum was then centrifuged $5 \mathrm{~min}$ at $500 \mathrm{~g}$ to remove cells, and 30 minutes at $25000 \mathrm{~g}$ to remove cellular debris. For the COVID-19 cohort, serum was used from SARSCoV-2 infected patients that were hospitalized due to COVID-19 symptoms. As control, serum was obtained from healthy volunteers at the UMC Utrecht without COVID-19 symptoms. All samples were collected in accordance with the Institutional Review Board of the University Medical Center (UMC) Utrecht or the National University of Singapore.

\section{Protease inhibitors}

The protease inhibitor cocktail (cOmplete ${ }^{\mathrm{TM}}$, EDTA-free) was purchased from Roche and used at half of the recommended concentration for lysates. Pepstatin A was purchased from Fisher Scientific, E64 from Sanbio, GM6001 from Merck, Leupeptin from Roche, Eap, EapH1 and EapH2 were recombinantly produced as previously described (24). The proteinase 3 inhibitor Bt-PYDnVP (25) (compound 10, $\left(\mathrm{O}-\mathrm{C}_{6} \mathrm{H}_{4}-4-\mathrm{Cl}\right)_{2}$ ) was generously provided by Dr. Brice Korkmaz and Prof. Dr. Adam 
Lesner and used at a concentration of $10 \mu \mathrm{M}$.

\section{Cloning and recombinant SSIRL-1 protein production}

To produce cDNA constructs, gBlocks ${ }^{\circledR}$ (Integrated DNA Technologies) were ordered that encode VSTM1-v2 and sSIRL-1 ${ }^{\text {ecto }}$ with a C-terminal His-tag (see Supplementary Table 1 for the DNA sequence, and Supplementary Fig 1 for the amino acid sequence of the recombinant proteins). The gBlocks were inserted into a pcDNA 3.1+ Zeocine plasmid using Gibson assembly master mix (New England Biolabs). The cDNA construct encoding LAIR-1 ectodomain (sLAIR-1 ${ }^{\text {ecto }}$ ) has been previously described (26).

Recombinant proteins were produced using the Freestyle ${ }^{\mathrm{TM}} 293$ Expression System (Thermo Fisher Scientific) according to manufacturer's instructions. Four days after transfection, supernatants were collected and filtered through a $0.45 \mu \mathrm{M}$ Minisart Filter (Sartorius). The His-tagged proteins in the supernatants were purified using HIStrap FF columns (GE Healthcare) according to manufacturer's instructions. Briefly, the columns were attached to an ÄKTAprime ${ }^{\text {TM }}$ (GE Healthcare) and equilibrated with binding buffer ( $20 \mathrm{mM} \mathrm{Na}_{3} \mathrm{PO}_{4}, 500 \mathrm{mM} \mathrm{NaCl}, 20 \mathrm{mM}$ Imidazole, $\mathrm{pH}$ 7.4). Next, supernatants were mixed with binding buffer in a 1:1 ratio, filtered through a Stericup $0.22 \mu \mathrm{M}$ filter

114 (Millipore), and loaded onto the ÄKTAprime ${ }^{\mathrm{TM}}$. After loading, binding buffer was applied until a steady baseline was reached. Next, elution buffer $\left(20 \mathrm{mM} \mathrm{Na}_{3} \mathrm{PO}_{4}, 500 \mathrm{mM} \mathrm{NaCl}, 500 \mathrm{mM}\right.$ Imidazole, $\mathrm{pH}$ 7.4) was added for a one-step elution of the proteins. Protein-containing fractions were pooled and rebuffered to PBS using VIVAspin columns (5,000 MWCO PES; Sartorius). Protein yield was determined with a BCA protein assay (Pierce ${ }^{\mathrm{TM}}$; Thermo Scientific).

\section{SDS-PAGE and Western blot}

121 To remove $\mathrm{N}$-linked glycosylation, recombinant proteins were treated with PNGase $\mathrm{F}$ (New England Biolabs) according to manufacturer's instructions. Next, the proteins were incubated 5 minutes at $95^{\circ} \mathrm{C}$ in Laemmli sample buffer (Bio-Rad laboratories), with or without addition of $\beta$-mercaptoethanol

124 (Sigma-Aldrich Chemie). Proteins were separated by SDS-PAGE on Any kD Mini-PROTEAN TGX Precast

125 Protein Gels (Bio-Rad Laboratories) and either stained directly with coomassie blue (Merck) or

126 transferred onto $0.45 \mu \mathrm{m}$ PVDF membranes (Merck) for western blot analysis.

For western blot analysis, membranes were blocked in TBS containing 0.05\% Tween-20 (TBS-

$128 \mathrm{~T})$ and $5 \% \mathrm{BSA}$, incubated with $\mathrm{mAb} 1 \mathrm{~A} 5(2 \mathrm{\mu g} / \mathrm{mL}$ in TBS-T with $1 \% \mathrm{BSA})$, followed by staining with 129 goat-anti-mouse IgG F(ab')2-HRP (Jackson ImmunoResearch; 1:5000 diluted in TBS-T with 1\% BSA).

130 All incubations were $1 \mathrm{~h}$ at RT and followed by extensive washing with TBS-T. Finally, proteins were 131 visualized using ECL Western blot reagent (Fisher Scientific) and the ChemiDoc ${ }^{\mathrm{TM}}$ imaging system 132 (Bio-Rad). 
To determine PR3 cleavage, $20 \mu \mathrm{g} / \mathrm{mL}$ sSIRL-1 ${ }^{\text {ecto }}$ or VSTM1-v2 were incubated with $2 \mu \mathrm{g} / \mathrm{mL}$ PR3 in PBS with $0.5 \mathrm{M} \mathrm{NaCl}$ and incubated $3 \mathrm{~h}$ at $25^{\circ} \mathrm{C}$, followed by SDS-PAGE and Western blot analysis as described above, except that rabbit-anti-mouse IgG-HRP (DAKO; 1:10.000 diluted in TBS-T with $1 \%$ BSA) was used as secondary antibody.

\section{SSIRL-1 ELISA}

139 To measure sSIRL-1 in cell supernatants, 96-wells flat-bottom MAXIsorp plates (Nunc) were coated overnight at $4^{\circ} \mathrm{C}$ with capture mAb $1 \mathrm{~A} 5(5 \mu \mathrm{g} / \mathrm{mL}$ in PBS, $50 \mu \mathrm{L} /$ well). After washing with PBS $0.05 \%$

$141(\mathrm{v} / \mathrm{v})$ Tween-20, plates were blocked with $100 \mu \mathrm{L} /$ well blocking buffer (1\% (w/v) BSA, 3\% (w/v) dry

142 milk in PBS). Next, plates were washed and incubated with undiluted cell supernatants and the 143 standard curve consisting of serially diluted sSIRL-1 ${ }^{\text {ecto }}$ in PBS $1 \%$ BSA (50 $\mu \mathrm{L} /$ well), overnight at $4^{\circ} \mathrm{C}$.

144 The following day, plates were washed and incubated with biotinylated mAb 3D3 for 1 hour at RT,

145 followed by washing and incubation with streptavidin poly-HRP $(0.1 \mu \mathrm{g} / \mathrm{mL}$; Sanquin) for 1 hour at

146 RT. Finally, plates were washed and incubated with $100 \mu \mathrm{L} /$ well TMB-substrate (Biolegend/ITK). The

147 substrate reacted approximately 8 minutes, after which color development was stopped by adding

$148100 \mu \mathrm{L} /$ well $1 \mathrm{M} \mathrm{H}_{2} \mathrm{SO}_{4}$. Absorbance was measured at $450 \mathrm{~nm}$ on the CLARIOstar ${ }^{\circledR}$ (BMG Labtech).

149 Absorbance at $570 \mathrm{~nm}$ was used for background correction. All incubations, except coating of the 150 capture antibody, were done on a shaker.

151 The same procedure was used to measure sSIRL-1 in plasma, serum, urine or sputum 152 samples, with two exceptions: a different blocking buffer was used ( $3 \%$ (w/v) BSA in PBS), and 153 samples were pre-incubated 15 minutes on a shaker with $20 \mu \mathrm{g} / \mathrm{mL}$ HAMA blocking reagent 154 (Fitzgerald) before adding the samples to the ELISA plate, to prevent a-specific interactions. SSIRL-1 may have a different molecular weight than the recombinant SSIRL-1 ${ }^{\text {ecto }}$ that was used for the standard curve.

\section{Neutrophil stimulation with protease inhibitors}

160 Neutrophils were isolated from peripheral blood using density gradient centrifugation on Ficoll (GE

161 Healthcare). The neutrophil pellet was incubated with ammonium chloride buffer to lyse the

162 erythrocytes. The remaining neutrophils were washed and suspended in RPMI 1640 containing 10\%

$163(\mathrm{v} / \mathrm{v}) \mathrm{FCS}$ and 1\% (v/v) PS. Neutrophils were then stimulated with 50-100 ng/mL tumor necrosis factor 164 (TNF; Miltenyi) or $100 \mu \mathrm{g} / \mathrm{mL}$ of the Dectin-1 ligand Curdlan (Wako biochemical) in flatbottom plates 165 (Nunc) at $37^{\circ} \mathrm{C}$, with or without addition of protease inhibitors. After 2 to 4 hours, neutrophils were 166 centrifuged 5 minutes at $500 \mathrm{~g}$ to collect the supernatants. Cells were used for flow cytometry 
167 analysis. Supernatants were centrifuged once more for 30 minutes at $25000 \mathrm{~g}$ at $4^{\circ} \mathrm{C}$ to remove

168 cellular debris, followed by ELISA measurements.

169

170 PLB-985 cell treatment with neutrophil serine proteases

171 The transduction and culture method of PLB-985 cells with SIRL-1 overexpression have been

172 previously described (16). Cells were treated $2 \mathrm{~h}$ at $37^{\circ} \mathrm{C}$ with neutrophil elastase (Elastin Products

173 Company), cathepsin G (Biocentrum), or proteinase 3 (Elastin Products Company) (all $1 \mu \mathrm{M})$, followed

174 by flow cytometry analysis.

175

176 Flow cytometry

177 To determine SIRL-1 expression, cells were washed once with FACS buffer and stained with mAb 1A5

178 or $3 F 5$ conjugated to AF647 or appropriate isotype controls (BD Biosciences) for 20 minutes at $4^{\circ} \mathrm{C}$.

179 Subsequently, the cells were washed twice with FACS buffer and finally taken up in FACS buffer with

180 addition of 7AAD (BD Bioscience) for viability staining. Cells were analyzed using the BD FACS Canto II

181 and FlowJo software (Treestar, Ashland, OR). For neutrophil activation experiments, neutrophils

182 were gated as in Supplementary Fig 3. Neutrophil purity was always $>90 \%$, based on forward scatter

183 (FSC) and sideward scatter (SSC).

184

\section{Statistical analysis}

186 Statistical analyses were performed using GrapPad Prism software (version 8.3.0). For each graph,

187 the statistical test and number of biological replicates $(n)$ are described in the figure legends. 


\section{Development of sSIRL-1 ELISA}

191 To develop a sSIRL-1 ELISA, we first produced recombinant His-tagged SSIRL-1 proteins: SIRL-1 ectodomain (SSIRL-1 ${ }^{\text {ecto }}$ ) and VSTM1-v2, representing products of ectodomain shedding and alternative splicing, respectively (See Fig $1 \mathrm{~A}$ for a schematic representation of the proteins, and Supplementary Fig $1 \mathrm{~A}$ for the amino acid sequences). Both proteins were $\mathrm{N}$-glycosylated, as shown by a shift in molecular weight after PNGase-F treatment and SDS-PAGE and Western blot analysis (Fig 1B, C). Deglycosylated VSTM1-V2, with a predicted MW of $21.6 \mathrm{kDa}$, had an apparent size of $37 \mathrm{kDa}$, which is consistent with the MW found in a previous study (22). Deglycosylated SSIRL-1 ${ }^{\text {ecto }}$, with a predicted MW of $13.8 \mathrm{kDa}$, had an apparent size of $16 \mathrm{kDa}$. The size of the proteins was not affected by reduction with 2-mercaptoethanol, indicating the proteins did not form dimers with disulfide bonds.

For the ELISA, sSIRL-1 ${ }^{\text {ecto }}$ was used as a standard, SIRL-1 mAb clone $1 \mathrm{~A} 5$ as capture antibody and SIRL-1 mAb clone 3D3 as detection antibody. In a competition assay, clone 1A5 and 3D3 did not interfere with each other for binding to SIRL-1, and thus recognize different epitopes (Supplementary Fig 1B). The ELISA detected SSIRL-1 ${ }^{\text {ecto }}$ and VSTM1-v2 equally well, with a lower limit of detection of 8 pM (Fig 1D). The ectodomain of the inhibitory receptor LAIR-1 (sLAIR-1 ${ }^{\text {ecto }}$ ), which has $31 \%$ sequence identity with SSIRL-1 ${ }^{\text {ecto }}$, was not detected in the ELISA, indicating specificity of the ELISA (Fig 1D). We spiked SSIRL-1 ${ }^{\text {ecto }}$ into heparin plasmas that were SSIRL-1 negative in our ELISA. The spike was recovered in all plasma dilutions tested (Fig $1 \mathrm{E}$ ), indicating that plasma is not interfering with the SSIRL-1 measurement. Next, we spiked SSIRL-1 ${ }^{\text {ecto }}$ into human pooled serum (HPS) and subjected it to 10 freeze thaw cycles, or incubation at $37^{\circ} \mathrm{C}, 56^{\circ} \mathrm{C}$ or $65^{\circ} \mathrm{C}$ for 30 minutes or 1 hour. sSIRL-1 concentration was stable in all freeze thaw cycles but decreased after 30 minutes incubation at $65^{\circ} \mathrm{C}$

212 (Supplementary Fig 1C). Taken together, we developed a sensitive and specific assay to measure

213 SSIRL-1 protein concentration and showed that SSIRL-1 can be detected in presence of human plasma 214 components and is stable during multiple freeze-thaw cycles.

\section{sSIRL-1 is present in vivo and increased in respiratory inflammation}

217 To investigate the presence of SSIRL-1 protein in vivo, we used the ELISA to measure SSIRL-1 in 218 plasma of healthy individuals, stratified per genotype of the rs612529T/C SNP. rs612529C associates with decreased SIRL-1 expression on monocytes, but not on granulocytes (14, 15). sSIRL-1 was 
(Fig 2A). There was a tendency toward a lower percentage of samples with detectable sSIRL-1 in individuals with a rs612529 C allele, but these differences were not statistically significant (Fig 2B).

To investigate the presence of sSIRL-1 in an inflammatory context, we measured SSIRL-1 in patients with COVID-19 or RSV bronchiolitis, which are both characterized by excessive neutrophil recruitment and activation (reviewed in $(27,28)$. We detected SSIRL-1 in approximately $70 \%$ of sera drawn from hospitalized adult COVID-19 patients, and the mean SSIRL-1 concentration was significantly higher than in control serum (Fig 2C-D). sSIRL-1 concentration in serum of COVID-19 patients was not affected by sex, age, nor the time since the start of symptoms or hospitalization (Supplementary Fig 2A, B, D, E). Within patients, sSIRL-1 concentration fluctuated in serum collected at two time points (Supplementary Fig 2C). Serum samples in this cohort were collected at nonstandardized time points, and we had restricted availability to clinical data, thereby limiting further analysis on the correlation between SSIRL-1 concentration and disease activity.

We previously showed that RSV bronchiolitis patients have decreased SIRL-1 expression on sputum neutrophils compared to peripheral blood neutrophils $(17,29)$, which is in line with our hypothesis that activated neutrophils shed the ectodomain of SIRL-1. Indeed, in patients with severe RSV bronchiolitis, we detected sSIRL-1 in 15 out of 16 sputa, and the mean sSIRL-1 concentration in sputum was significantly increased compared to plasma (Fig 2E). We also detected sSIRL-1 in the urine of the RSV patients, in similar concentrations as in plasma (Fig 2F). In summary, we show that SSIRL-1 concentration is mostly undetectable in healthy individuals, but increased in hospitalized COVID-19 or severe RSV bronchiolitis patients.

\section{Activated neutrophils shed SSIRL-1 via proteolytic cleavage}

To test if activated neutrophils indeed shed SIRL-1, we stimulated neutrophils from healthy controls in vitro with TNF or curdlan, with or without addition of a broad-spectrum protease inhibitor cocktail. We analyzed SIRL-1 expression on neutrophils by flow cytometry, and SSIRL-1 concentration in the supernatant by ELISA. In agreement with our previous work (16), the percentage of SIRL-1 $1^{+}$ neutrophils decreased after activation (Fig 3A, B). Concomitantly, we detected SSIRL-1 in the supernatant (Fig 3C). Treatment with the protease inhibitor cocktail prevented this (Fig 3A-C), indicating that activated neutrophils release SSIRL-1 via proteolytic cleavage.

\section{SSIRL-1 is shed by proteinase 3}

252 To examine which protease cleaves SIRL-1, we activated neutrophils with TNF in combination with 253 inhibitors against major classes of proteases: pepstatin A for aspartic proteases, E64 for cysteine 254 proteases, GM6001 for metalloproteases, leupeptin for serine and cysteine proteases, and aprotinin 255 for serine proteases. Treatment with $10 \mu \mathrm{M}$ aprotinin resulted in a small but significant increase in 
256 the percentage of SIRL-1-expressing cells after TNF stimulation, suggesting that SIRL-1 is shed by a

257 serine protease (Fig 4A). Thus, we further investigated SIRL-1 cleavage by the serine proteases that

258 are predominantly secreted from activated neutrophils; cathepsin G, neutrophil elastase, and

259 proteinase 3 (PR3) (30). Treatment of SIRL-1-overexpressing PLB-985 cells with PR3 resulted in a

260 modest but consistent decrease in SIRL-1 expression, whereas cathepsin G and elastase did not affect

261 SIRL-1 expression on these cells (Fig 4B-C). To confirm that PR3 cleaves SIRL-1, we activated

262 neutrophils with TNF in presence of a specific PR3 inhibitor. Indeed, the PR3 inhibitor partially

263 prevented the loss of SIRL-1 expression on TNF-activated neutrophils in all donors tested (Fig 4D-E).

264 Finally, treatment of SSIRL-1 ${ }^{\text {ecto }}$ and VSTM1-V2 with PR3 in a purified system resulted in proteolytic

265 cleavage as assessed by SDS-PAGE and Western Blot (Fig 4F). Thus, we show that PR3 cleaves SIRL-1.

\section{S. aureus protein Eap inhibits sSIRL-1 shedding by neutrophils}

268 SIRL-1 is activated by $\alpha$-type phenol-soluble modulins (PSMs) from Staphylococci (19). S. aureus is

269 known for its large repertoire of secreted factors that can influence the host immune response,

270 including inhibitors against neutrophil proteases. Among these, S. aureus produces extracellular

271 adherence protein (Eap) and the homologues EapH1 and EapH2, which specifically inhibit neutrophil

272 serine proteases, including PR3 (24). We therefore questioned whether Eap can inhibit shedding of

273 SIRL-1 by neutrophils. Remarkably, treatment with Eap almost completely prevented the loss of

274 membrane-expressed SIRL-1 after TNF stimulation of neutrophils (Fig 5A, B). A similar trend was seen

275 after treatment with EapH2, whereas treatment with EapH1 had no effect on membrane SIRL-1

276 expression. In PLB-985 cells, Eap and EapH1 both inhibited SIRL-1 cleavage by exogenous PR3 (Fig

2775 5). Together, these data indicate that Eap can inhibit proteolytic cleavage of SIRL-1. 


\section{DISCUSSION}

Here, we developed an ELISA to measure SSIRL-1 concentration (Fig 1) and are the first to show that SSIRL-1 protein is present in vivo (Fig 2).

SSIRL-1 concentration was increased in sputum of RSV bronchiolitis patients compared to plasma, suggesting release of sSIRL-1 at the site of infection (Fig 2E). sSIRL-1 was also detectable in sputum of control infants, which can be explained by previous observations that sputum neutrophils of these control patients are activated (17), possibly due to mechanical ventilation (31). From the site of infection, sSIRL-1 may leak into the circulation, as there was a trend of increased sSIRL-1 in RSV patient plasma compared to control plasma, although this comparison was limited by the low number of control plasmas (Fig 2E). Similarly, sSIRL-1 concentration was increased in serum of hospitalized COVID-19 patients compared to control serum (Fig 2C). Lastly, sSIRL-1 was also detectable in urine of RSV patients (Fig 2F), indicating that, similar to soluble LAIR-1 (26), sSIRL-1 is cleared by the kidneys.

Several studies have indicated a role of neutrophils in the pathophysiology of COVID-19 (reviewed in (28). Using a machine learning algorithm on a broad panel of inflammatory markers, neutrophil-related markers predicted critical illness of COVID-19 patients most strongly (32). These markers included resistin, lipocalin-2 and hepatocyte growth factor, which are all released by degranulating neutrophils. Similarly, PR3 was highly present in sputum of COVID-19 patients (33), and its concentration predicted COVID-19 disease severity (34). Due to restricted availability of data and the collection of serum at non-standardized time points, we could not correlate sSIRL-1 concentration to COVID-19 disease progression, clinical parameters or inflammatory markers in our cohort. Future studies will have to clarify if sSIRL-1 may serve as a biomarker to predict COVID-19 disease severity, or other diseases characterized by high neutrophil activation.

We found that SIRL-1 is cleaved from activated neutrophils by PR3 (Fig 3-4). In addition to secretion of soluble PR3, activated neutrophils can express PR3 on the plasma membrane on a subpopulation of cells (35). Membrane-bound PR3 (mPR3) has been suggested to bind to the plasma membrane via CD177, other membrane-expressed proteins, or directly to the lipid bilayer (36-38). We compared shedding of SIRL-1 on FACS-sorted CD177 ${ }^{+}$versus CD177 neutrophils and found that CD177 expression did not affect SSIRL-1 shedding (unpublished observations). Still, we showed that SIRL-1 surface expression decreased in a subpopulation of neutrophils after activation in vitro (Fig 3A, 4D,

3115 5B), which may reflect cells with high mPR3 expression. On the other hand, SIRL-1 expression was 
homogeneously low on neutrophils in sputum of RSV bronchiolitis patients $(17,29)$. Hence, the relative contribution of soluble PR3 and mPR3 to SIRL-1 shedding remains to be determined.

Finally, we show that shedding of SIRL-1 by activated neutrophils was prevented by Eap, a neutrophil serine protease inhibitor secreted by S. aureus (Fig 5). The homologues EapH1 and EapH2 were less effective in preventing SIRL-1 shedding from activated neutrophils. In a previous study, using short peptide substrates, EapH1 and EapH2 also had a lower capacity to inhibit PR3 than Eap (Eap, $\mathrm{K}_{\mathrm{i}}=0.23 \mathrm{nM}$; EapH1, $\mathrm{K}_{\mathrm{i}}=1.0 \mathrm{nM}$; EapH2, $\mathrm{K}_{\mathrm{i}}=21 \mathrm{nM}$ ) (24) (Fig 5A, B). Alternatively, EapH1 and EapH2 may differ in their ability to inhibit mPR3, as mPR3 has been shown to be more resistant to PR3 inhibitors than soluble PR (39). The latter finding may also explain the partial effectiveness of the PR3 inhibitor used in this study, and the differential abilities of leupeptin and aprotinin to inhibit SIRL-1 shedding (Fig 4A, 5A).

In addition to ectodomain shedding, sSIRL-1 may derive from the splice variant VSTM1-v2 $(22,40)$. VSTM1-V2 mRNA expression was increased in PBMCs of Rheumatoid Arthritis patients compared to controls (40). However, it remains to be determined whether endogenous VSTM1-v2 protein is present in vivo. Both forms of sSIRL-1 were recognized by our ELISA (Fig 1D), thus not allowing for discrimination between these forms. Further research into VSTM1-v2 protein would benefit from the development of an antibody that recognizes the intracellular tail of SIRL-1, which is present in VSTM1-V2 but not in shed SSIRL-1.

Currently, we can only speculate on the function of SIRL-1 shedding. We previously argued that IIRS that are constitutively expressed on a cell form a threshold to prevent unnecessary immune activation. Some of these threshold receptors, so-called disinhibition receptors, are downregulated after an activating stimulus surpasses the initial threshold, to facilitate subsequent cellular activation (2). SIRL-1 is such an disinhibition receptor, based on its constitutive high expression on monocytes and granulocytes in peripheral blood and lung $(12,14,15)$ and downregulation during inflammation

$338(17,29)$. We thus propose that the function of SIRL-1 shedding is to rapidly remove SIRL-1 to facilitate 339 for a strong anti-microbial response, once the threshold for activation is surpassed.

Of course, the inhibitory function of SIRL-1 and hence the effect of SIRL-1 shedding also depends on expression of its ligands. We found that SIRL-1 is activated by S100 proteins (20), cathelicidin LL-37, and PSMs from Staphylococci (19). In inflammatory conditions with local tissue damage and DAMP release, neutrophil released LL-37 and S100 proteins may act mostly on newly incoming neutrophils 
PSMs are produced by both pathogenic and harmless Staphylococci (41). SIRL-1 ligation by

346 PSMs may be beneficial for the host, for example by facilitating tolerance of resting neutrophils to

347 harmless Staphylococci such as S. epidermidis, but still allowing for full neutrophil activation once

348 SIRL-1 is shed in an inflammatory context. Interestingly, S. aureus, the most pathogenic member of

349 the Staphylococcus family, is unique in its secretion of Eap proteins (24). S. aureus may use Eap to

350 inhibit SIRL-1 shedding to benefit from the preserved inhibitory function of membrane-expressed

351 SIRL-1. Of particular interest is a recent study showing that $S$. aureus also requires Eap to prevent

352 degradation of PSM $\alpha 3$ by neutrophil serine proteases (42), indicating that Eap potentially preserves

353 expression of SIRL-1 as well as its ligands.

354

355 In conclusion, we measured increased SSIRL-1 concentration in COVID-19 and RSV bronchiolitis

356 patients and provided mechanistic insight into the loss of SIRL-1 from activated neutrophils. Future

357 studies will have to further elucidate the functional implications of sSIRL-1 release, and its potential

358 use as a biomarker. 


\section{Acknowledgements}

361 We thank Brice Korkmaz and Adam Lesner for generously providing the PR3 inhibitor, Anouk van

362 Haperen for asistance with cloning and production of recombinant sSIRL-1 proteins, Jop Wattel for 363 assistance with the development of the sSIRL-1 ELISA, Prof. Wang De Yun for subject recruitment for 364 the SSIC samples, Tamara Brouwers for assistance with neutrophil stimulation assays, Maaike Ressing 365 for the suggestion to test the effect of $S$. aureus protease inhibitors on SIRL-1 shedding, and Femke 366 van Wijk for valuable suggestions on the manuscript. This work was supported by a Vici grant from 367 the Netherlands Organization for Scientific Research (NWO, grant no. 91815608) and a ZonMW grant 368 (grant no. 10430012010024).

\section{Authorship}

371 LM and HR conceptualized the study. HR, GW, and DG performed the experiments. HR and GW

372 analyzed the data. ED, SN, HL and KR were responsible for the design and sample collection of the

373 COVID-19 patient cohort, SB and LB for the RSV patient cohort, and AA and OR for the rs612529

374 cohort. PM was involved in the development and validation of SIRL-1 mAb clone 3F5. SR and DS

375 provided Eap, EapH1, and EapH2, and contributed to the design and interpretation of the

376 experiments with these proteins. LM, LB and SR supervised the study. HR wrote the initial draft of

377 the manuscript. All authors contributed to the writing and editing of the final manuscript. LM and SN 378 acquired funding for the study.

\section{Declaration of interest:}

None 
(A) Schematic representation of SIRL-1 and its two potential soluble forms; VSTM1-V2 and SSIRL-1 ${ }^{\text {ecto }}$. (B-C) SDS-PAGE analysis of VSTM1-v2 and SSIRL-1 ${ }^{\text {ecto }}$, with or without pre-treatment with PNGase F or $\beta$-mercaptoethanol (2-BME). Proteins were either stained directly by coomassie ( $B$ ) or transferred to a membrane and stained with SIRL-1 mAb clone 1A5 (C). Arrows indicate the position of VSTM1-V2 (v2), sSIRL-1 ${ }^{\text {ecto }}$ (ecto) or PNGase F. (D) sSIRL-1 ${ }^{\text {ecto }}$, VSTM1-v2 and negative control sLAIR-1 ${ }^{\text {ecto }}$ were titrated in an in-house developed SSIRL-1 ELISA ( $n \geq 3$, one representative example is shown). (E) sSIRL-1 negative heparin plasmas $(n=5)$ were titrated and spiked with $70 \mathrm{pM}$ sSIRL-1 ${ }^{\text {ecto }}$. sSIRL-1 concentration was measured by ELISA, symbols represent the mean \pm SD. The statistical difference between the spike and the recovery of SSIRL-1 ${ }^{\text {ecto }}$ at different plasma dilutions was tested using an one sample Wilcoxon test, $\mathrm{ns}=$ not significant.

\section{Fig 2. SSIRL-1 is increased in COVID-19 and RSV bronchiolitis patients}

SSIRL-1 was measured by ELISA in plasma, urine and sputum. (A-B) SSIRL-1 concentration in plasma from 53 healthy donors, stratified per genotype of the rs612529 SNP (T/T, $n=22 ; T / C, n=17 ; C / C$, $n=14)$. (C-D) sSIRL-1 concentration in serum of hospitalized COVID-19 patients ( $n=163$ ) and control serum ( $n=51$ ). (E) sSIRL-1 concentration in heparin plasma or sputum of mechanically ventilated infants with severe RSV bronchiolitis or mechanically ventilated infants without infection (controls). Control plasma, $n=4$; RSV plasma, $n=17$; control sputum, $n=2$; RSV sputum, $n=16$. (F) sSIRL-1 concentration in paired plasma and urine samples of infants with severe RSV bronchiolitis $(n=8)(A, C$, E, F) Each dot represents one donor, the green bars represent the mean. The shaded area indicates the lower limit of detection (LLOD). Samples with undetectable sSIRL-1 were given a value of $0.5 x$ LLOD. Statistical differences were calculated using a Kruskal-Wallis test with Dunn's correction (A, E), a Mann Whitney test (C), or a Wilcoxon test (F). (B, D) The percentage of samples with detectable SSIRL-1. The error bars indicate the $95 \%$ confidence interval, calculated with Wilson-Brown. The statistical differences were calculated using a Fisher's exact test $(B, D)$, in combination with significant.

Fig 3. Activated neutrophils shed SIRL-1

414 Neutrophils were isolated from healthy donors and stimulated $4 \mathrm{~h}$ at $37^{\circ} \mathrm{C}$ with curdlan $(100 \mu \mathrm{g} / \mathrm{mL})$ 415 or TNF (100 ng/mL), with or without addition of a protease inhibitor cocktail. (A-B) SIRL-1 expression on neutrophils was analyzed by flow cytometry. Shown are representative histograms of the 
417 fluorescence intensity of cells stained with a SIRL-1 antibody (clone 1A5) (closed histogram) or an

418 isotype control (open histogram) (A) and the quantification of the percentage of SIRL-1 ${ }^{+}$cells (B).

419 Each symbol represents one donor, $n=6$. (C) Supernatants from stimulated neutrophils were analyzed

420 by sSIRL-1 ELISA. Each symbol represents one donor, $n=5$. Statistical significance was determined

421 using a two-way ANOVA with Geisser-Greenhouse correction and Holm-Sidak's multiple comparison

422 test (B-C), * $\mathrm{p} \leq .05, * * \mathrm{p} \leq .01, * * * \mathrm{p} \leq .001$.

423 Fig 4. SIRL-1 is cleaved by PR3

424 (A, D, E) Neutrophils were isolated from healthy donors and stimulated $2 \mathrm{~h}$ at $37^{\circ} \mathrm{C}$ with TNF (50

$425 \mathrm{ng} / \mathrm{mL}$ ), with or without addition of inhibitors against major protease classes $(\mathrm{A} ; 10-40 \mu \mathrm{M})$ or a PR3

426 inhibitor (D-E; $10 \mu \mathrm{M}$ ). Cells were stained with a SIRL-1 antibody (clone 3F5) and analyzed by flow

427 cytometry. (A) The bars indicate the percentage of SIRL-1+ $1^{+}$cells (mean \pm SD), each symbol represents

428 a donor, $n=3$. (D) Representative histograms of the fluorescence intensity of cells stained with a SIRL-

4291 antibody and (E) the quantification of the percentage of SIRL-1 $1^{+}$cells (each symbol with connected

430 line represents a donor), $n=7$. (B-C) PLB-985 cells with SIRL-1 overexpression were treated $2 \mathrm{~h}$ with

431 neutrophil elastase, cathepsin $\mathrm{G}$, or proteinase 3 (all $1 \mu \mathrm{M}$ ), followed by flow cytometry analysis

$432(n=4)$. Shown are representative histograms of the fluorescence intensity of cells stained with a SIRL-

4331 antibody (clone 3F5) (B) and the quantification of the median fluorescent intensity (MFI),

434 normalized to the MFI of untreated cells (C; mean \pm SD, each symbol represents one experiment). (F)

435 SSIRL-1 ${ }^{\text {ecto }}$ and VSTM1-v2 were left untreated (-) or treated with buffer control (ctrl) or PR3 for $3 \mathrm{~h}$ at

$43625^{\circ} \mathrm{C}$, and analyzed by SDS-PAGE and Western Blot. The membrane was stained with a SIRL-1

437 antibody (clone 1A5). The arrows indicate the position of VSTM1-V2 or SSIRL-1 ${ }^{\text {ecto }}$. One representative

438 experiment of $n=3$ is shown. Statistical significance was determined using a mixed-effects model with

439 Dunnett's multiple comparisons test (A; TNF treatment alone was compared to TNF treatment with

440 each of the protease inhibitors), a 1-way ANOVA with Dunnett's multiple comparison test (C) or a

441 mixed-effects model with Sidak's multiple comparisons test (E), all with Geisser-Greenhouse

442 correction, $* p \leq .05$.

\section{Fig 5. S. aureus protein Eap inhibits SIRL-1 shedding}

444 (A-B) Neutrophils were isolated from healthy donors and stimulated for $2 \mathrm{~h}$ at $37^{\circ} \mathrm{C}$ with TNF (50

$445 \mathrm{ng} / \mathrm{mL}$ ), with or without addition of 10-30 $\mu \mathrm{g} / \mathrm{mL}$ Eap, EapH1, or EapH2 (indicated with H1 or H2,

446 respectively). Cells were stained with a SIRL-1 mAb (clone 3F5) and analyzed by flow cytometry, $n=4-$

447 6. (A) The percentage of SIRL-1 $1^{+}$cells (mean \pm SD), each symbol represents a donor. (B)

448 Representative histograms of the fluorescence intensity of cells stained with a SIRL-1 antibody. (C)

449 PLB-985 cells with SIRL-1 overexpression were treated $2 \mathrm{~h}$ with $1 \mu \mathrm{M}$ proteinase 3 , with or without

450 addition of Eap or EapH1 $(30 \mu \mathrm{g} / \mathrm{mL})$. SIRL-1 expression was analyzed by flow cytometry. The bars 
bioRxiv preprint doi: https://doi.org/10.1101/2022.03.03.482795; this version posted March 3, 2022. The copyright holder for this preprint (which was not certified by peer review) is the author/funder, who has granted bioRxiv a license to display the preprint in perpetuity. It is made available under aCC-BY-NC-ND 4.0 International license.

451 indicate the percentage of SIRL-1 $1^{+}$cells (mean \pm SD), each symbol represents an experiment, $n=3-4$.

452 Statistical significance was determined using a mixed-effects model with Dunnett's multiple

453 comparisons test (A) or Holm-Sidak's multiple comparisons test (C), both with Geisser-Greenhouse

454 correction, $* p \leq .05, * * p \leq .01$. 


\section{LITERATURE}

456

457

458

459

460

461

462

463

464

465

466

467

468

469

470

471

472

473

474

475

476

477

478

479

480

481

482

483

484

485

486

487

488

489

490

491

492

493

494

495

496

497

498

499

500

501

502

503

504

1. Steevels TA, Meyaard L. 2011. Immune inhibitory receptors: essential regulators of phagocyte function. Eur. J. Immunol 41: 575-87

2. Rumpret M, Drylewicz J, Ackermans LJE, Borghans JAM, Medzhitov R, Meyaard L. 2020. Functional categories of immune inhibitory receptors. Nat Rev Immunol

3. Gu D, Ao X, Yang Y, Chen Z, Xu X. 2018. Soluble immune checkpoints in cancer: production, function and biological significance. J Immunother Cancer 6: 132

4. Lie WR, McDonald J, Russell D, Banerjee M, Zimmermann D, Kornmeier C, Pepin D. 2021. Analysis of soluble immune checkpoint proteins using quantitative multiplex microbeadbased immunoassays. Journal of Immunology 206

5. Ohnishi H, Kobayashi H, Okazawa H, Ohe Y, Tomizawa K, Sato R, Matozaki T. 2004. Ectodomain shedding of SHPS- 1 and its role in regulation of cell migration. $J$ Biol Chem 279: 27878-87

6. Fornasa G, Groyer E, Clement M, Dimitrov J, Compain C, Gaston AT, Varthaman A, KhallouLaschet J, Newman DK, Graff-Dubois S, Nicoletti A, Caligiuri G. 2010. TCR stimulation drives cleavage and shedding of the ITIM receptor CD31. J Immunol 184: 5485-92

7. Nielsen C, Ohm-Laursen L, Barington T, Husby S, Lillevang ST. 2005. Alternative splice variants of the human PD-1 gene. Cell Immunol 235: 109-16

8. Terahara K, Yoshida M, Taguchi F, Igarashi O, Nochi T, Gotoh Y, Yamamoto T, TsunetsuguYokota Y, Beauchemin N, Kiyono H. 2009. Expression of newly identified secretory CEACAM1(a) isoforms in the intestinal epithelium. Biochem Biophys Res Commun 383: 340-6

9. Lebbink RJ, van den Berg MCW, De Ruiter T, Raynal N, van Roon JAG, Lenting PJ, Jin B, Meyaard L. 2008. The soluble LAIR-2 antagonizes the collagen/LAIR-1 inhibitory immune interaction. J Immunol 180: 1662-9

10. Pepin D, Godeny M, Russell D, Mehta P, Lie WR. 2018. Profiling of soluble immune checkpoint proteins as potential non-invasive biomarkers in colorectal cancer and sepsis. Journal of Immunology 200

11. Kong Y, Wang Y, Wu X, Han J, Li G, Hua M, Han K, Zhang H, Li A, Zeng H. 2020. Storm of soluble immune checkpoints associated with disease severity of COVID-19. Signal Transduct Target Ther 5: 192

12. Steevels TAM, Lebbink RJ, Westerlaken GHA, Coffer PJ, Meyaard L. 2010. Signal Inhibitory Receptor on Leukocytes-1 (SIRL-1) is a novel functional inhibitory immune receptor expressed on human phagocytes. J Immunol 184: 4741-8

13. Xie M, Li T, Li N, Li J, Yao Q, Han W, Ruan G. 2015. VSTM-v1, a potential myeloid differentiation antigen that is downregulated in bone marrow cells from myeloid leukemia patients. J. Hematol. Oncol 8: 25

14. Kumar D, Puan KJ, Andiappan AK, Lee B, Westerlaken GH, Haase D, Melchiotti R, Li Z, Yusof N, Lum J, Koh G, Foo S, Yeong J, Alves AC, Pekkanen J, Sun LD, Irwanto A, Fairfax BP, Naranbhai V, Common JE, Tang M, Chuang CK, Jarvelin MR, Knight JC, Zhang X, Chew FT, Prabhakar S, Jianjun L, Wang Y, Zolezzi F, Poidinger M, Lane EB, Meyaard L, Rotzschke O. 2017. A functional SNP associated with atopic dermatitis controls cell type-specific methylation of the VSTM1 gene locus. Genome Med 9: 18

15. von Richthofen HJ, Gollnast D, van Capel TMM, Giovannone B, Westerlaken GHA, Lutter L, Oldenburg B, Hijnen D, van der Vlist M, de Jong EC, Meyaard L. 2020. Signal Inhibitory Receptor on Leukocytes-1 is highly expressed on lung monocytes, but absent on mononuclear phagocytes in skin and colon. Cell Immunol 357: 104199

16. Steevels TA, van Avondt K, Westerlaken GH, Walk J, Bont L, Coffer PJ, Meyaard L. 2013. Signal Inhibitory Receptor on Leukocytes-1 (SIRL-1) negatively regulates the oxidative burst in human phagocytes. Eur. J Immunol 43: 1297-308 
bioRxiv preprint doi: https://doi.org/10.1101/2022.03.03.482795; this version posted March 3 , 2022. The copyright holder for this preprint (which was not certified by peer review) is the author/funder, who has granted bioRxiv a license to display the preprint in perpetuity. It is made available under aCC-BY-NC-ND 4.0 International license.

17. Besteman SB, Callaghan A, Hennus MP, Westerlaken GHA, Meyaard L, Bont LL. 2020. Signal inhibitory receptor on leukocytes (SIRL)-1 and leukocyte- associated immunoglobulin-like receptor (LAIR)-1 regulate neutrophil function in infants. Clin Immunol 211: 108324

18. Van Avondt K, van der Linden M, Naccache PH, Egan DA, Meyaard L. 2016. Signal Inhibitory Receptor on Leukocytes-1 Limits the Formation of Neutrophil Extracellular Traps, but Preserves Intracellular Bacterial Killing. J Immunol 196: 3686-94

19. Rumpret $M$, von Richthofen $H J$, van der Linden $M$, Westerlaken GHA, Talavera Ormeno $C$, van Strijp JAG, Landau M, Ovaa H, van Sorge NM, Meyaard L. 2021. Signal inhibitory receptor on leukocytes-1 recognizes bacterial and endogenous amphipathic alpha-helical peptides. FASEB J 35: e21875

20. Rumpret $\mathrm{M}$, von Richthofen $\mathrm{HJ}$, van der Linden $\mathrm{M}$, Westerlaken GHA, Talavera Ormeno $\mathrm{C}$, Low TY, Ovaa H, Meyaard L. 2021. Recognition of S100 proteins by Signal Inhibitory Receptor on Leukocytes-1 negatively regulates human neutrophils. Eur J Immunol 51: 2210-7

21. Rumpret M, von Richthofen HJ, Peperzak V, Meyaard L. 2022. Inhibitory pattern recognition receptors. J Exp Med 219

22. Guo X, Zhang Y, Wang P, Li T, Fu W, Mo X, Shi T, Zhang Z, Chen Y, Ma D, Han W. 2012. VSTM1-V2, a novel soluble glycoprotein, promotes the differentiation and activation of Th17 cells. Cell Immunol 278: 136-42

23. Andiappan AK, Puan KJ, Lee B, Yeow PT, Yusof N, Merid SK, Kumar D, Lum J, Foo S, Koh G, Poidinger M, Zolezzi F, e QC, Consortium B, Wang Y, Melen E, Rotzschke O. 2021. Inverse association of FCER1A allergy variant in monocytes and plasmacytoid dendritic cells. J Allergy Clin Immunol 147: 1510-3 e8

24. Stapels DA, Ramyar KX, Bischoff M, von Kockritz-Blickwede M, Milder FJ, Ruyken M, Eisenbeis J, McWhorter WJ, Herrmann M, van Kessel KP, Geisbrecht BV, Rooijakkers SH. 2014. Staphylococcus aureus secretes a unique class of neutrophil serine protease inhibitors. Proc Natl Acad Sci U S A 111: 13187-92

25. Guarino C, Gruba N, Grzywa R, Dyguda-Kazimierowicz E, Hamon Y, Legowska M, Skorenski M, Dallet-Choisy S, Marchand-Adam S, Kellenberger C, Jenne DE, Sienczyk M, Lesner A, Gauthier F, Korkmaz B. 2018. Exploiting the S4-S5 Specificity of Human Neutrophil Proteinase 3 to Improve the Potency of Peptidyl Di(chlorophenyl)-phosphonate Ester Inhibitors: A Kinetic and Molecular Modeling Analysis. J Med Chem 61: 1858-70

26. Olde Nordkamp MJM, van Roon JA, Douwes M, De Ruiter T, Urbanus RT, Meyaard L. 2011. Enhanced secretion of Leukocyte-Associated Immunoglobulin-like Receptor (LAIR)-2 and soluble LAIR-1 in rheumatoid arthritis: LAIR-2 is a more efficient antagonist of the LAIR-1collagen inhibitory interaction than soluble LAIR -1. Arthritis Rheum 63: 3749-57

27. Geerdink RJ, Pillay J, Meyaard L, Bont L. 2015. Neutrophils in respiratory syncytial virus infection: A target for asthma prevention. J Allergy Clin Immunol 136: 838-47

28. Reusch N, De Domenico E, Bonaguro L, Schulte-Schrepping J, Bassler K, Schultze JL, Aschenbrenner AC. 2021. Neutrophils in COVID-19. Front Immunol 12: 652470

29. Geerdink RJ, Hennus MP, Westerlaken GHA, Abrahams AC, Albers KI, Walk J, Wesselink E, Janssen R, Bont L, Meyaard L. 2018. LAIR-1 limits neutrophil extracellular trap formation in viral bronchiolitis. J Allergy Clin Immunol 141: 811-4

30. Pham CT. 2006. Neutrophil serine proteases: specific regulators of inflammation. Nat Rev Immunol 6: 541-50

31. Imanaka H, Shimaoka M, Matsuura N, Nishimura M, Ohta N, Kiyono H. 2001. Ventilatorinduced lung injury is associated with neutrophil infiltration, macrophage activation, and TGF-beta 1 mRNA upregulation in rat lungs. Anesth Analg 92: 428-36

32. Meizlish ML, Pine AB, Bishai JD, Goshua G, Nadelmann ER, Simonov M, Chang CH, Zhang $H$, Shallow M, Bahel P, Owusu K, Yamamoto Y, Arora T, Atri DS, Patel A, Gbyli R, Kwan J, Won CH, Dela Cruz C, Price C, Koff J, King BA, Rinder HM, Wilson FP, Hwa J, Halene S, Damsky W, van Dijk D, Lee Al, Chun HJ. 2021. A neutrophil activation signature predicts critical illness and mortality in COVID-19. Blood Adv 5: 1164-77 
bioRxiv preprint doi: https//doi.org/10.1101/2022.03.03.482795; this version posted March 3, 2022. The copyright holder for this preprint (which was not certified by peer review) is the author/funder, who has granted bioRxiv a license to display the preprint in perpetuity. It is made available under aCC-BY-NC-ND 4.0 International license.

33. Seren S, Derian L, Keles I, Guillon A, Lesner A, Gonzalez L, Baranek T, Si-Tahar M, MarchandAdam S, Jenne DE, Paget C, Jouan Y, Korkmaz B. 2021. Proteinase release from activated neutrophils in mechanically ventilated patients with non-COVID-19 and COVID-19 pneumonia. Eur Respir $J 57$

34. Huang W, Li M, Luo G, Wu X, Su B, Zhao L, Zhang S, Chen X, Jia M, Zhu J, Su W, Zhang D. 2021. The Inflammatory Factors Associated with Disease Severity to Predict COVID-19 Progression. J Immunol 206: 1597-608

35. Halbwachs-Mecarelli L, Bessou G, Lesavre P, Lopez S, Witko-Sarsat V. 1995. Bimodal distribution of proteinase 3 (PR3) surface expression reflects a constitutive heterogeneity in the polymorphonuclear neutrophil pool. FEBS Lett 374: 29-33

36. Hajjar E, Mihajlovic M, Witko-Sarsat V, Lazaridis T, Reuter N. 2008. Computational prediction of the binding site of proteinase 3 to the plasma membrane. Proteins 71: 1655-69

37. Jerke U, Marino SF, Daumke O, Kettritz R. 2017. Characterization of the CD177 interaction with the ANCA antigen proteinase 3. Sci Rep 7: 43328

38. Korkmaz B, Kuhl A, Bayat B, Santoso S, Jenne DE. 2008. A hydrophobic patch on proteinase 3, the target of autoantibodies in Wegener granulomatosis, mediates membrane binding via NB1 receptors. J Biol Chem 283: 35976-82

39. Guarino C, Legowska M, Epinette C, Kellenberger C, Dallet-Choisy S, Sienczyk M, Gabant G, Cadene M, Zoidakis J, Vlahou A, Wysocka M, Marchand-Adam S, Jenne DE, Lesner A, Gauthier F, Korkmaz B. 2014. New selective peptidyl di(chlorophenyl) phosphonate esters for visualizing and blocking neutrophil proteinase 3 in human diseases. J Biol Chem 289: 3177791

40. Wang D, Li Y, Liu Y, He Y, Shi G. 2016. Expression of VSTM1-v2 Is Increased in Peripheral Blood Mononuclear Cells from Patients with Rheumatoid Arthritis and Is Correlated with Disease Activity. PLoS One 11: e0146805

41. Cogen AL, Yamasaki K, Sanchez KM, Dorschner RA, Lai YP, MacLeod DT, Torpey JW, Otto M, Nizet V, Kim JE, Gallo RL. 2010. Selective Antimicrobial Action Is Provided by Phenol-Soluble Modulins Derived from Staphylococcus epidermidis, a Normal Resident of the Skin. Journal of Investigative Dermatology 130: 192-200

42. Kretschmer D, Breitmeyer R, Gekeler C, Lebtig M, Schlatterer K, Nega M, Stahl M, Stapels D, Rooijakkers S, Peschel A. 2021. Staphylococcus aureus Depends on Eap Proteins for Preventing Degradation of Its Phenol-Soluble Modulin Toxins by Neutrophil Serine Proteases. Front Immunol 12: 701093 
Fig. 1) Development of sSIRL-1 ELISA

A

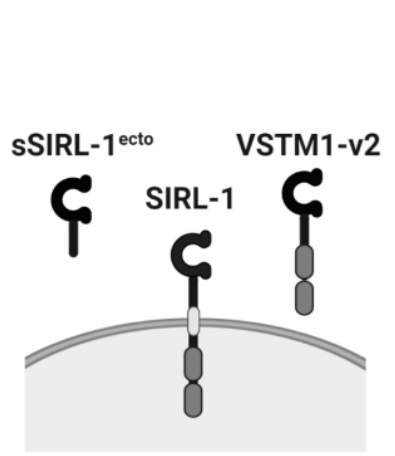

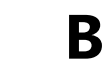

2BME

PNGase $\mathrm{F}$

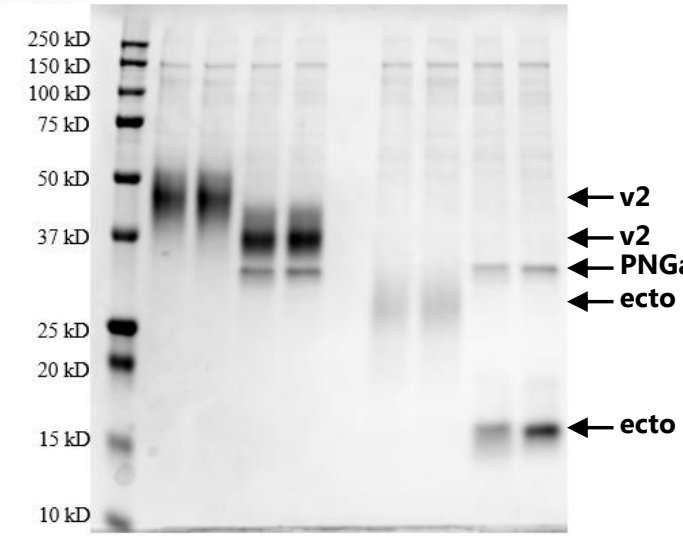

Coomassie stain

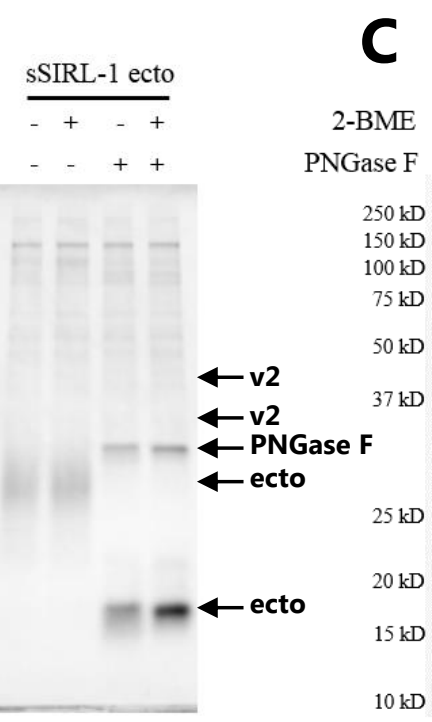

$10 \mathrm{kD}$
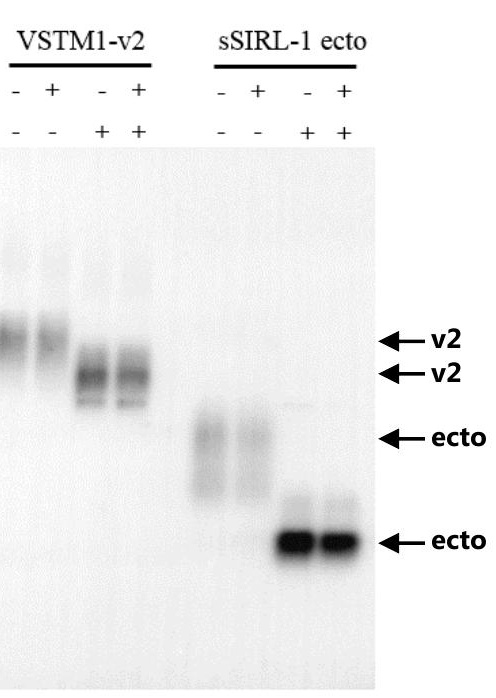

WB: anti-SIRL-1

E
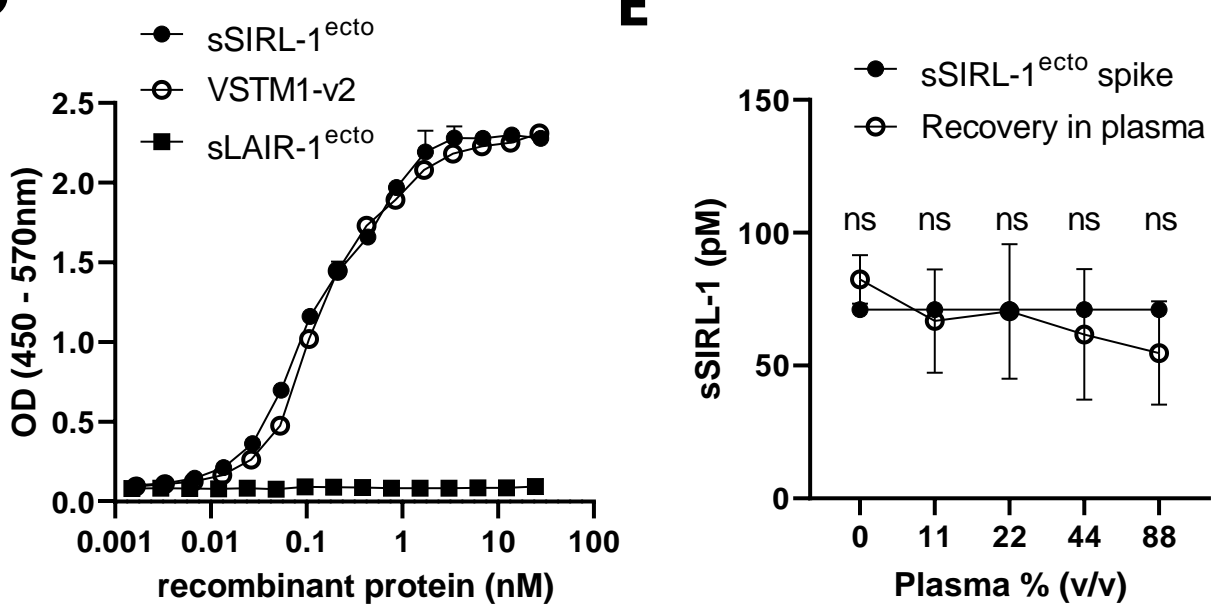
Fig. 2) SSIRL-1 is increased in COVID-19 and RSV bronchiolitis patients
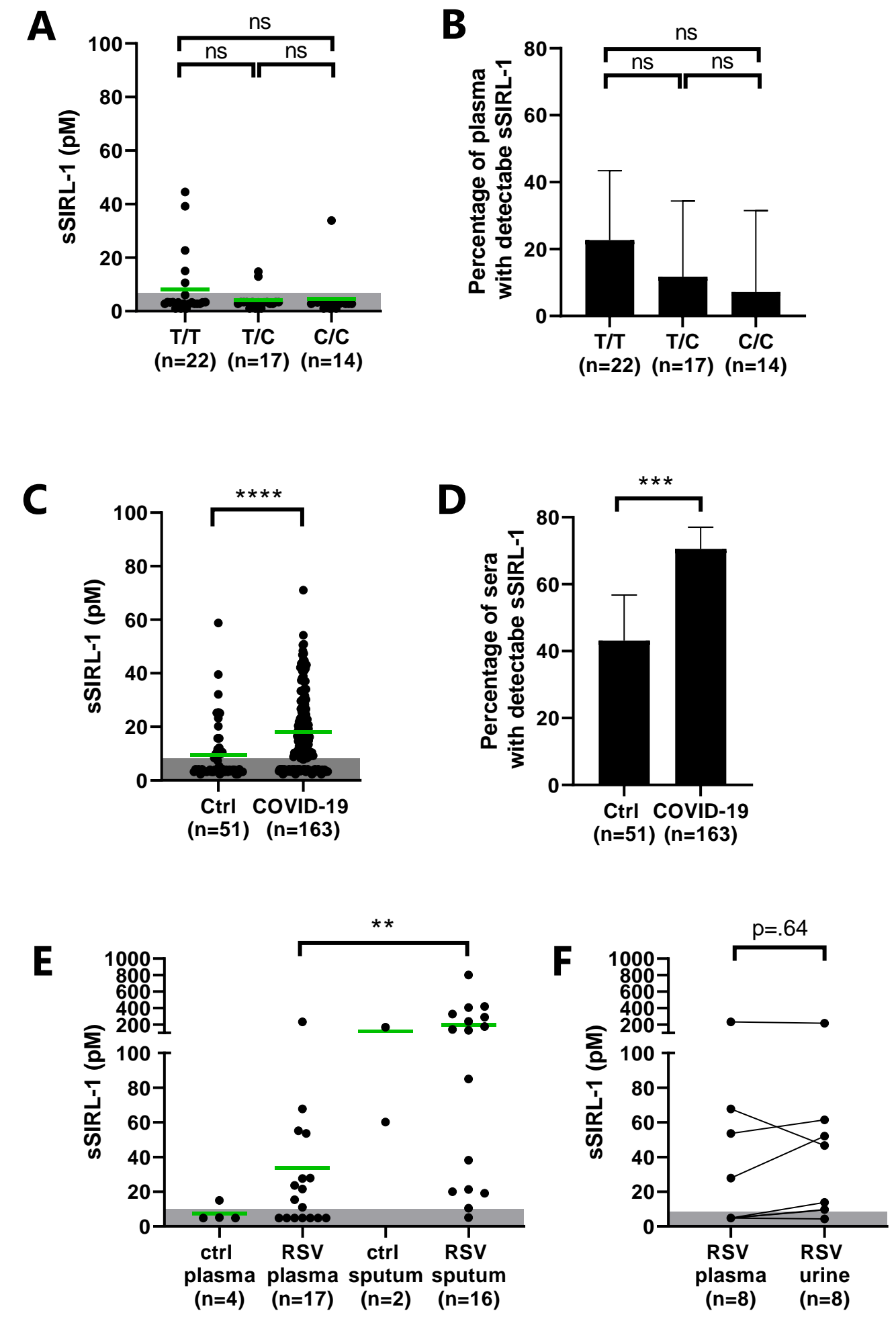
Fig. 3) Activated neutrophils shed sSIRL-1

A

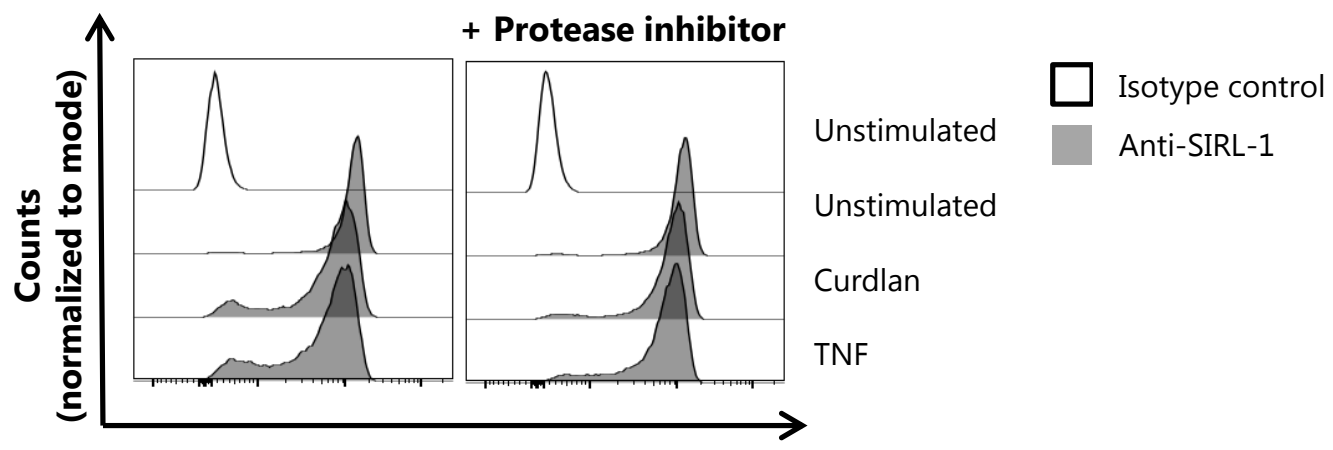

Fluorescence intensity

B
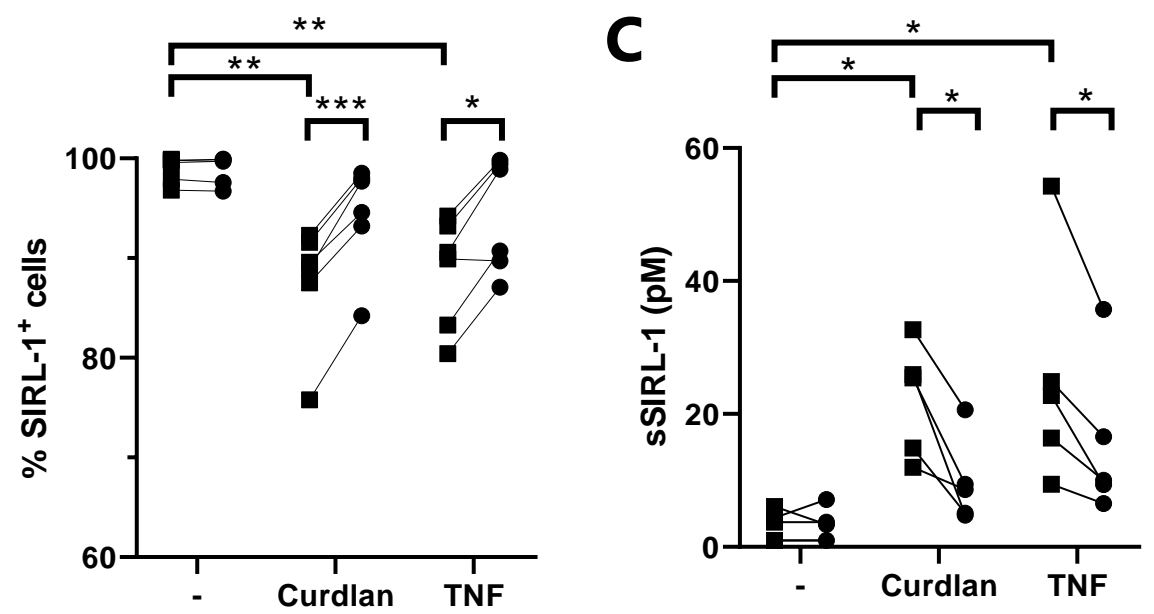

- Without Protease inhibitor

- With Protease inhibitor 
Fig. 4) SIRL-1 is cleaved by PR3
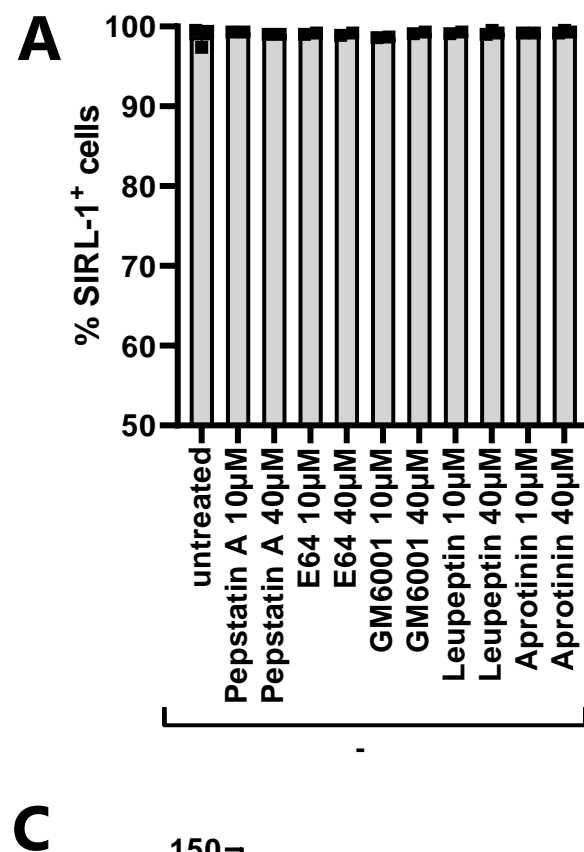

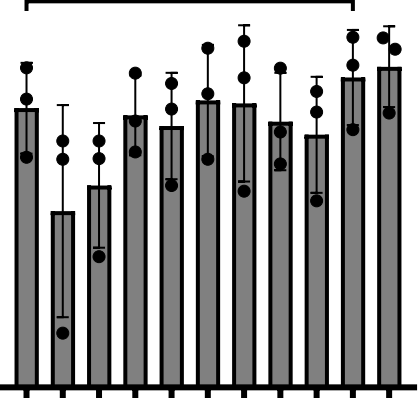

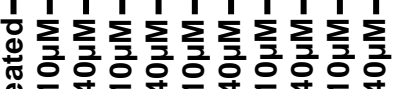

is

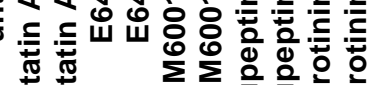

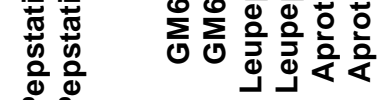

ญ ญ

TNF

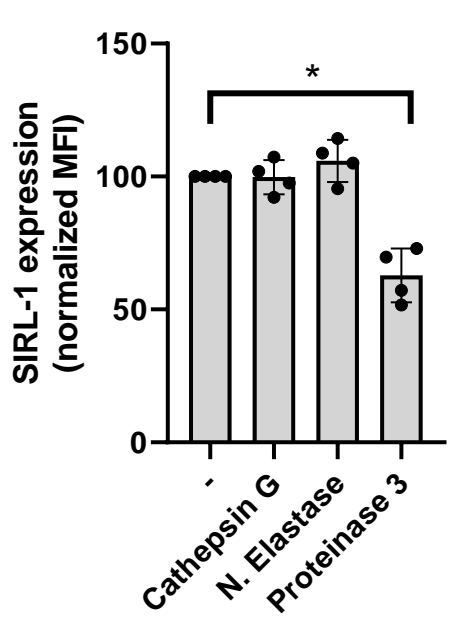

D

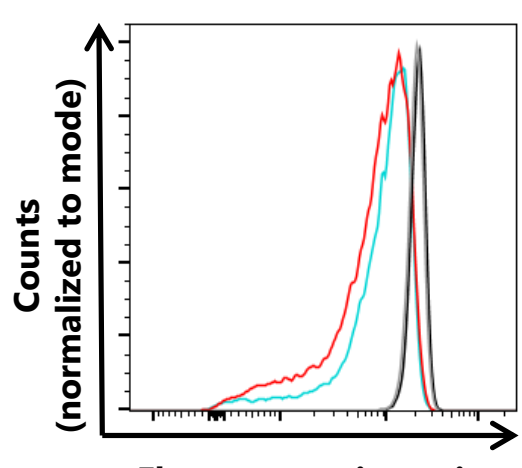

Fluorescence intensity

DMSO control

PR3-inh

TNF + DMSO ctrl \begin{tabular}{ll|l} 
sSIRL-1 ecto & VSTM1-v2 & TNF + PR3-inh.
\end{tabular}

$\mathbf{F}$

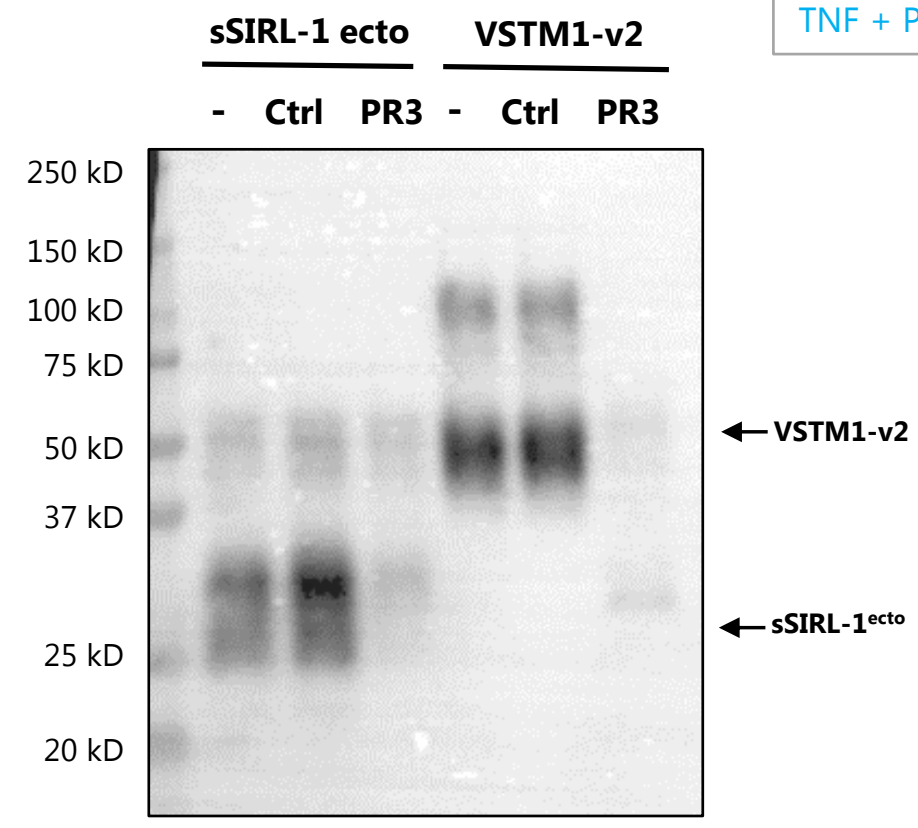

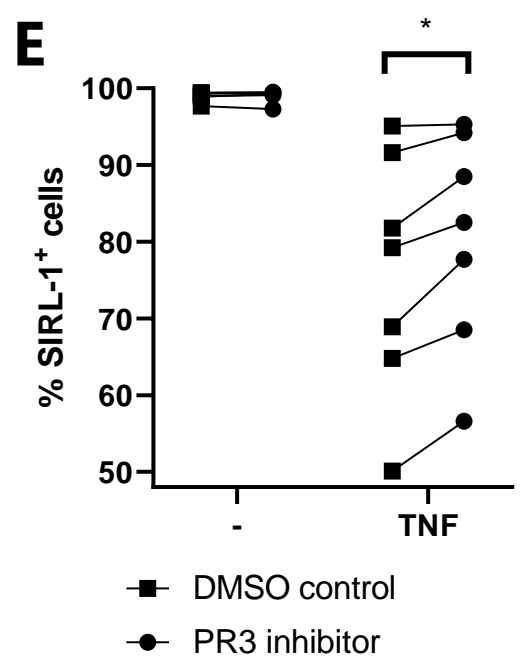

-2 DMSO control

- PR3 inhibitor
Untreated

Cathepsin G

N. Elastase

Proteinase 3

Fluorescence intensity 
Fig. 5) S. aureus protein Eap inhibits SIRL-1 shedding

A

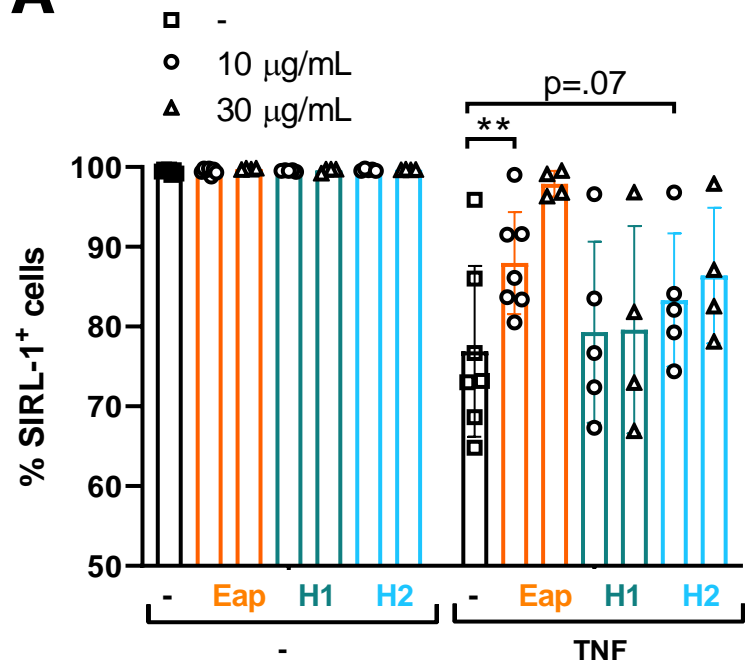

C

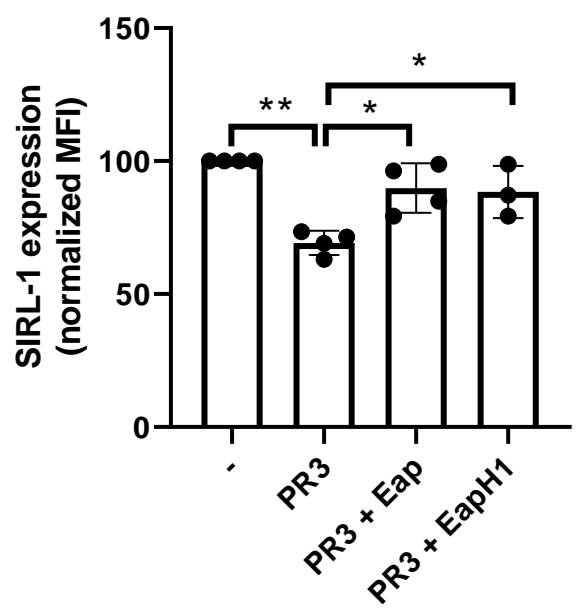

B

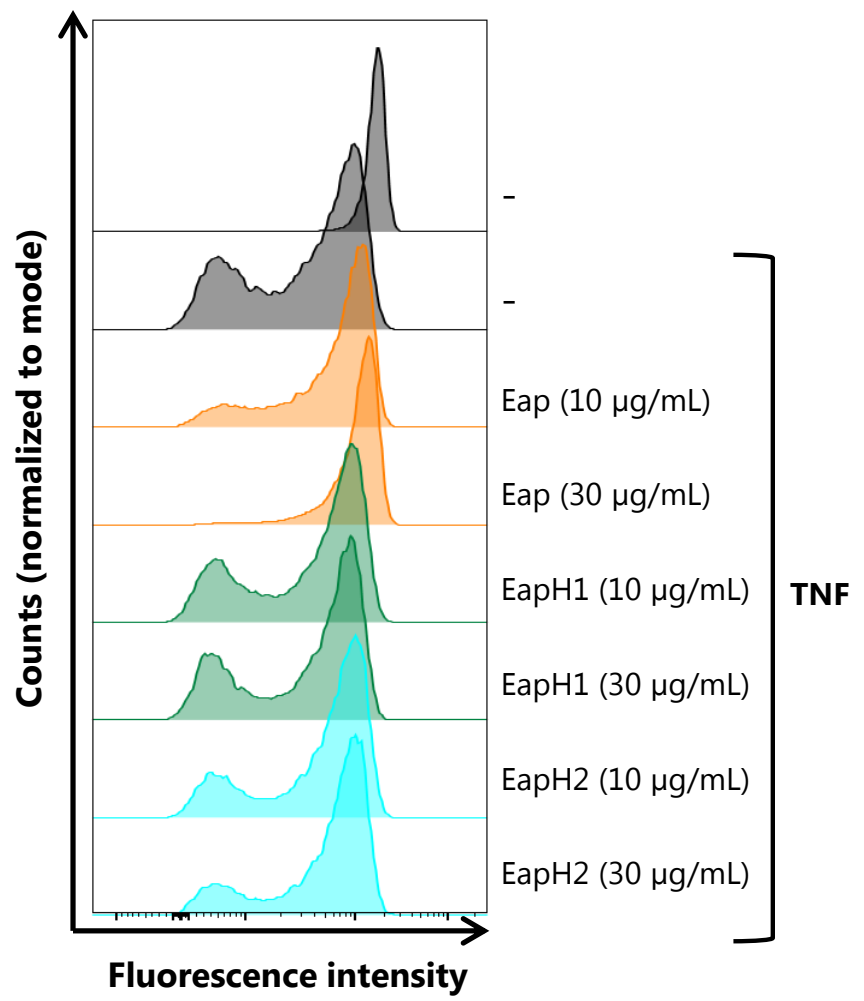

